tude, we should like to have seen the essentially vector nature of the subject made more manifest; and at intervals enforced by examples drawn from physics and mechanics. There seems no good reason why in elementary text-books of trigonometry practical applications should in the main be confined to the ship-tower-flagstaff type of examples.

(4) The text-book on engineering mathematics by Mr. H. H. Harrison comprises chapters on arithmetic, algebra, trigonometry, mensuration, logarithms, squared paper, and the calculus. The presentation of the subject by the author is crude and uninteresting, no examples are provided for practice, and the book cannot be recommended for any class of student.

\section{TROPICAL MEDICINE.}

Lectures on Tropical Diseases, being the Lane Lectures for 1905 delivered at the Cooper Medical College, San Francisco. By Sir Patrick Manson. Pp. viii +23o. (London: Constable and Co., Ltd., I905.) Price $7 s .6 d$. net.

TROPICAL pathology no doubt owes much of its

fascination to the fact that new diseases, or the causes of old diseases, have only within the last decade been completely elucidated, and that every year, if not every month, fresh facts appear and fresh subjects of inquiry suggest themselves. Thus almost before the rtiology of sleeping sickness was fully elucidated, students of tropical pathology were given a fresh subject of inquiry from the discovery of the cause of the dreaded "tick fever" of Tete on the Zambesi, and of other parts of tropical Africa. When the interest in the Anophelinæ and Stegomyia fasciata had somewhat waned, the tropical pathologist had his attention diverted to tsetse-flies, and then again the hue and cry was in the direction of ticks, especially in Africa towards Ornithodorus moubata, the transmitter of the spirochæte of "tick fever."

In India the malariologist must have recently received a severe shock to find that many of his most familiar cases, which he designated "malaria cachexia with enlarged spleen," are in all probability due to an entirely new parasite, or at least the parasite can be found in the organs of such cases. In tropical pathology Africa has provided many of these novelties, but, in the opinion of medical men who have travelled widely in tropical Africa, there is not now much probability left of the production of a completely " new" disease. We do not, of course, imply that many minor discoveries do not remain to be made, and, indeed, even great ones, such as the causes of yellow fever and beri-beri; and to the investigator who is content with elucidating minor problems these fascinating lectures will afford numerous examples of the kind of work that still remains to be done.

But a word of caution is perhaps necessary; for the reader is presented with a host of interesting suggestions and speculations, and unless he advances cautiously and weighs these carefully in the light of experience, he may well take the phantom hypothesis for fact, for it would be possible in this particular No I905, VOL. 74$]$ branch of pathology to adduce examples where hypothesis simply has actually retarded the acquisition of knowledge. We would prefer rather to see the investigator laboriously accumulate facts and to base on these his own hypothesis rather than, starting with a ready-made hypothesis, to try and adapt his facts to it. With this caution we think these lectures should serve as a stimulant to the jaded investigator depressed by the slowness of his own advance, as he perhaps remembers that it took Ross some two years or so to work out the mosquito cycle of the malaria parasite, and that the first hypothesis as to the path followed by the parasite in the mosquito was a wrong one.

While, then, a perusal of these lectures has raised some doubts in our minds as to the general validity of presenting those, presumably novices, with a number of interesting suggestions, yet for even the veteran there is abundance of sound common sense to be found here which he will do well to treasure up. If, further, we venture to criticise various statements in detail, we do not do so in a spirit of opposition, but simply as an expression of a difference of opinion. The author (p. 2) refers to helminthology as " until recently an insignificant if not a despised branch of pathology"; but surely this is somewhat forgetful of the claims on our gratitude and respect of such helminthologists as Leukart, Dujardin, Rudolphi, Cobbold, Küchenmeister, \&c. We can only in part agree with the opinion that, regarded " as a cultivating medium, there is no difference between the juices and tissues of an Esquimaux and those of a Caucasian or those of a negro." For what else but a difference of medium is the explanation of the fact that the healthy countryman will survive wounds and infections that prove fatal to the less resistant townsman? It is partly a difference of medium in the host, we believe, that causes malaria to be a mild disease in temperate regions, and a deadly one in tropical climates, where in both cases we may be dealing with a single infection of a particular person. In what else does the good of change of air, a sea voyage, \&c., consist, but in producing a change of medium in the host in which, e.g., the dysentery amoba is living?

In treating of filariasis (p. 8o) we do not think the author sufficiently emphasises the fact that the final link in the chain of evidence connecting the mosquito with the transmission of filaria is wanting. Grassi and Noe's experiments on the transmission of filariæe to dogs by means of mosquitoes are by no means convincing, and to experiment on man is hardly possible. In the case of the malaria parasite the experiment has been done several times, but it was Schaudinn who actually first saw the malarial sporozoit penetrate the red cell. We had made the same experiment as Schaudinn on many occasions without success, except that we saw the sporozoit transformed into a body indistinguishable from a socalled "ring form," and if the investigator follows out the method given on p. 98 he will not see what Schaudinn describes. For Schaudinn expressly says that on using sporozoits taken from the salivary gland he got no results; it was oniy on using sporo- 
zoits taken from large oocysts in the stomach that he got (two) successful results.

In discussing the atiology of sleeping sickness we think the author scarcely puts Colonel Bruce's discovery in its proper light. Wo would say that without Castellani's observation possibly Bruce would not have thought of or discovered the trypanosome, just as Dutton might never have discovered the Trypanosoma gambiense had it not been for Forde. But to claim Castellani as the discoverer of the xtiology of slecping sickness is, we consider, hardly right. Further, the author appears to have some doubts as to whether this trypanosome is really the cause of the disease, and cites, by way of caution, the fact that similar evidence could have been adduced in favour of the embryo F. perstans. But to us it seems that the "evidence" in favour of $F$. perstans was never at any time on the same footing as that of Trypanosoma gambiense, and, as a matter of fact, collapsed immediately the hypothesis was testcd by facts.

We cannot here discuss the evidence in favour of regarding $T$. gambiense as the cause of slecping sickness, but it is supplied by a body of epidemiological, pathological, and experimental evidence surely conclusive.

Finally, the author suggests (p. I24) that, in the case of $T$. gambiense, the negro of the endemic areas of this parasite has acquired an immunity similar to that of antelopes in regard to $T$. brucei. But, so far as we are aware, there is not the slightest evidence of this, and, in fact, the evidence is to the contrary, viz. that where a negro has T'. gambiense in his blood he will surcly die sooner or later (of sleeping sickness).

We consider that for the medical man the most valuable portions of the book are those dealing with the diagnosis and treatment of tropical fevers, and these should be taken to heart, for it is not uncommon, for example, for a patient to dic of liver abscess who has been treated throughout for "fever"; but fever is not always malarial, as is too often supposed.

The book has numerous illustrations in the text, but, with some exceptions, these are not entirely successful. We would heartily recommend those who wish for a series of stimulating, unconventional lectures to peruse this book. J. W. W. STEPHENs.

PROGRESSIVE TEACHING IN PHYSIOLOGY. Recent Advances in Physiology and Biochemistry. Edited by Leonard Hill, M.B., F.R.S. Pp. xix + 740. (London: E. Arnold, 1906.) Price 18s, net.

$\Gamma \mathrm{HE}$ rapid advances that physiology is making are reflected not only in the journals that deal with research, but also in the vigour with which the teachers of the subject are applying themselves to their duties in relation to their students. At several centres in London there are every year now given courses of advanced lectures, open free to all the students of the London medical schools, in which they may hear from the lips of the investigators themselves the result of their research, and witness the most important of their experiments.

The book now before us is a corresponding expresNO. I 905 , VOL. 74$]$ sion of this teaching energy, and one can only hope that authors and publishers alike may find their venture a success. Students have not the time for hunting up original papers, but they ought readily to imbibe a summary of recent research when it is presented to them in an attractive way.

The collaborators deal with subjects on which each is competent to speak, because they have themselves worked at those they write about. Thus the editor, Mr. Leonard Hill, treats of the subjects of respiration and fat-metabolism. Dr. J. J. R. Macleod gives a summary of recent work in connection with carbohydrate metabolism, uric acid formation, and the immunity question. Another aspect of the respiratory process is dealt with by Dr. Pembrey, who also writes on internal secretions; and some interesting chapters on 1ymph production, absorption, and excretion by Dr. Beddard follow next.

All the subjects are treated in a lucid manner, and will give to advanced students a clear idea of the present position reached by physiologists on many of the thorny problems that beset the path of the original worker.

The opening articles of the volume, which are from the pen of Prof. B. Moore, come into a somewhat different category. He deals with the applications of physical chemistry to physiological phenomena, especially in connection with secretion, and the action of enzymes. He gives the latest views and results on this most important subject, and teachers and students alike owe him a debt of gratitude for his able treatment of these somewhat obscure questions. Those parts which relate to the rules and formula which regulate the processes of reaction-velocity and the like will be found rather difficult to many, for physiologists and medical students are, as a rule, rather rusty in their mathematics. But Prof. Moore's articles are not mere abstracts of the work of himself and others, for he has chosen them as the vehicle for the promulgation of a new doctrine, of which the keynote is struck in the opening chapter. The main object of his succeeding chapters is to convince the reader that this new conception is right, and will explain much that has hitherto been puzaling. The cell is treated as a transformer of energy, but the new energy produced, which is characteristic of living structures, cannot be brought into line with the known forms of energy in the inorganic world. It differs from heat and electricity, for instance, as much as, or more than, heat and electricity differ from each other, and he dubs it "biotic energy." Biotic energy is not, however, the old vitalistic principle revived under a new name, for it obeys the law of conservation of energy, and its investication is capable of numerical and exact treatment just as that of heat and electricity is. A review is not the place to enter into any detailed. criticism of such a view. The idea will serve to stimulate others to renewed research, and one foresees it will meet with considerable opposition in the future. Any doctrine which involves controversy is to be welcomed, and finality in the discovery of truth is brought nearer as the workers are provided with new theories as a basis of work.

W. D. $\mathrm{H}$. 